\title{
¿QUÉ PASA ACTUALMENTE EN LA TEORÍA DEL DERECHO ALEMANA?* Un breve bosquejo general
}

\author{
Minor E. Salas \\ Universidad de Costa Rica
}

\begin{abstract}
«Soviel Stimmen soviel Sprachen, kaum noch einander verständlich, viel Scharfsinn, selten spielende Streiflichter des Feinsinns oder das erschreckende und beglückende Wetterleuchten des Tiefsinns, am seltensten das schlicht für sich selbst zeugende Siegel der klassischen Einfachheit!» Gustav Radbruch (Rechtsphilosophie, § 3).
\end{abstract}

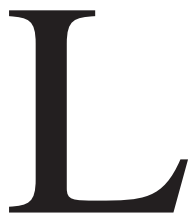

a actual Teoría del Derecho alemana no es desconocida en el ámbito hispanohablante. Todo lo contrario, los temas y autores que tienen por sede académica la tierra de Goethe han sido históricamente -y lo son hoy día- objeto de extensas discusiones en la literatura española y latinoamericana. ${ }^{1} \mathrm{Si}$ me he decidido a escribir estas líneas es porque estimo útil ofrecer una visión panorámica o de conjunto sobre los principales tópicos, corrientes y autores que se discuten actualmente en la Teoría del Derecho (Rechtstheorie) de estas latitudes (para detalles véase Alexy et al., en: Archiv für Rechts- und Sozialphilosophie, ARSP, suplemento Nr. 44). Resulta claro que por la naturaleza del trabajo me veo obligado a ser esencialmente descriptivo en mis apreciaciones y comentarios, pues la idea de un esquema general -y si se quiere pedagógico- no sería ejecutable si me dedicara a una crítica pormenorizada de cada una de las corrientes aludidas. Sin embargo, he tratado, en el marco de lo posible, de ofrecer al lector algunos comentarios críticos en torno a las principales fortalezas y debilidades de las teorías y autores que se mencionan.

* El presente artículo constituye una versión ampliada y algo modificada del epílogo que escribí para el libro de Hans Albert: «La Ciencia del Derecho como Ciencia Real» recientemente traducido por mí y que se publicará prontamente en la Editorial Temis S.A., Colombia, 2002, al cual remito para detalles importantes.

${ }^{1} \mathrm{Si}$ en lo sucesivo me limito a citar casi sólo la literatura alemana, no es por falsos «chauvinismos» o porque los estudios en España o en Latinoamérica sobre la materia sean escasos. Todo lo contrario, la discusión sobre Teoría y Filosofía del Derecho en estas latitudes es del más alto nivel. Mi omisión se debe más que todo a razones de espacio y al objeto de la investigación (la Teoría del Derecho alemana). 
Para efectos de exponer el panorama de la forma más clara posible, voy a dividir el ensayo en dos partes: la primera parte (I) es una corta reflexión histórica, pues me parece que resulta más fácil comprender la situación actual si se tiene presente, aunque sea a grandes rasgos, la evolución sufrida por la Teoría del Derecho alemana en las últimas décadas. La segunda parte (II) es la exposición de algunas de las concepciones que dominan la discusión en Alemania en dicha materia.

\section{Esbozo histórico de la Teoría del Derecho alemana}

Hay dos temas que llaman la atención cuando se estudia la Teoría del Derecho alemana, a saber: los distintos estadios por los que ha atravesado ésta y la disputa en torno al concepto mismo de «Teoría del Derecho».

A. Respecto al primer punto, se puede decir que el desarrollo histórico de la Teoría del Derecho alemana atraviesa después de 1945 -fecha en que se da una ruptura con la tradición anterior- por tres estadios concretos (sigo aquí parcialmente a Neumann, en: AA.VV. [1994a], pp. 145 y ss., y a Dreier, 1995):

1. El primer estadio se conoce como el «Renacimiento del Derecho natural».

2. El segundo estadio es una época de dominio de las «teorías analíticas» (latu sensu).

3. El tercer estadio es una época de dominio de las «teorías éticas» (normativismo).

De allí que si se desean utilizar unas categorías generales, algo así como «tipos ideales», que resulten fáciles de recordar, entonces me gustaría desarrollar la tesis de que el desarrollo histórico de la Teoría del Derecho en Alemania atraviesa en el último medio siglo por: 1) una fase metafísica 2) por una fase escéptica y 3 ) por una fase axiológica. Véamos un poco en detalle cada uno de estos tres periodos:

1. «La necesidad no sólo nos enseña a mendigar, sino también a filosofar», sentenciaba uno de los maestros de la filosofía alemana del siglo pasado, me refiero a Gustav Radbruch. Él tenía razón. Qué tan unidos se encuentran la calamidad humana y la filosofía (en especial la metafísica) se refleja con absoluta claridad si se estudia lo sucedido con la Filosofía del Derecho después de 1945. Es después de esta fecha que los juristas germanos se retrotraen sobre sí mismos con el objetivo de responder a la pregunta: ¿Cómo pudieron suceder tales horrores? Es en el intento por responder a esta interrogante existencial donde Radbruch, nuestro autor ya citado, y en un acto que traiciona a su genial lucidez, responderá: «iEl positivismo jurídico dejó a todos los juristas indefensos!» (1999, p. 215). Pero, indudablemente que no fue el «positivismo jurídico» quien maniató a los juristas, 
dejándolos impotentes (wehrlos) contra los crímenes y las arbitrariedades de los Nazis. No. Fue su propia conducta y su propia voluntad -o en todo caso la imposición de una voluntad ajena- pero no el «positivismo» que, en cuanto construcción teórico-normativa, es inexistente más allá de unos agentes humanos.

Pero este no es nuestro tema. Nuestro tema ahora es la trascendencia del Derecho y es justamente en esta trascendencia donde buscarán los juristas alemanes las respuestas a lo acaecido. Se hablará una y otra vez del «ewige Wiederkehr des Naturrechts» (del eterno retorno del Derecho natural, Rommen, 1947). Durante la década siguiente, la gran mayoría de las reflexiones básicas en torno al Derecho estuvieron dominadas por el intento de fundamentar las decisiones jurídicas en unos valores «objetivos» $\mathrm{y}$ «trascendentes». Para ello se acudió con frecuencia a los trabajos de Nicolai Hartmann y a los de Max Scheler. Pero también florecieron una buena cantidad de trabajos de la escuela tomista de Derecho natural (Fuchs, 1955; Funk, 1950; Messner, 1950), y de la iglesia católica y protestante (Brunner, 1943). Se cumplió así a cabalidad con la categórica máxima de Jean Paul de que el «Derecho natural sólo se encuentra en las iglesias o en las guerras». Incluso la jurisprudencia del Tribunal Superior Federal (BGH) fundamentó varias de sus sentencias acudiendo directamente a argumentos «naturalistas» o a «leyes morales» superiores (Rüthers, 1999, p. 248).

2. Pero el tiempo es el demiurgo del olvido. Después de casi una década, los argumentos basados en unos valores atemporales y ahistóricos comenzaron a parecer poco convincentes. El descontento creció. Fue Hans Welzel quien en 1951 con su libro Derecho natural y justicia material ( $N a$ turrecht und materiale Gerechtigkeit) arremetió seriamente contra muchos argumentos del Derecho natural al señalar: «Todos aquellos juicios de valor que coloca previamente el defensor del Derecho natural en las cosas son los que después vuelve a sacar a la luz, simplemente que ahora asignándoles el nombre de 'Derecho natural' o 'metafísico'» (p. 241). Con este malestar se iniciará un movimiento que busca fundamentar el Derecho ya no en categorías metafísicas sino más bien ontológicas. Es así como nace en Alemania una virulenta discusión que se conoce con el nombre de: «Die Natur der Sache» (naturaleza de las cosas) y que se extendería por varias décadas más (ejemplar: Kaufmann, 1965; Dreier, 1965; G. Sprenger, 1976). El problema central con que se enfrentaría este debate es el de la fundamentación de las categorías jurídicas partiendo de unas «estructuras lógico-objetivas»-como les llamaría Welzel- las cuales son impuestas a la consciencia humana por medio del orden inmanente que subyace a la realidad. Estas estructuras representarían algo así como las condiciones de posibilidad del ser y del pensar. 
Tiempo después, en especial con la publicación de dos obras: Tópica y Jurisprudencia en 1953 (Topik und Jurisprudenz) de Theodor Viehweg y Principio y norma en el proceso de desarrollo judicial del Derecho privado en 1956 (Grundsatz und Norm in der richterlichen Fortbildung des Privatrechts) de Josef Esser, se inicia una nueva fase en la Filosofía del Derecho alemana. Es aquí donde empieza el periodo que he llamado escéptico y que constituye a la vez la época más crítica y productiva de la Teoría del Derecho germana. Una de las características medulares de esta fase es la marcada preocupación en torno a los problemas metodológicos y con ello la incorporación oficial al curriculum académico de la Metodología Jurídica (de acuerdo Neumann, en: AA.VV. [1994b], pp. 158 y ss.). Dentro de esta nueva fase metodológica jugaría un papel importante la obra de Karl Engisch: Introducción al pensamiento jurídico, 1956 (Einführung in das juristische Denken), que prevalece hasta la fecha como un clásico en la materia. Es a lo interno de esta naciente discusión donde se ponen en entredicho, por ejemplo, categorías como las de: sistema jurídico, subsunción, interpretación, valoración, vínculo a la ley, etc. Se inicia con ello el largo debate en torno a dos formas o manifestaciones del razonamiento jurídico: el «Sistemdenken» (pensamiento sistemático) y el «Problemdenken» (pensamiento problemático). El trabajo más representativo e influyente en esta línea es el de Wilhelm Canaris: El concepto de sistema y el pensamiento sistemático en la ciencia jurídica, 1969 (Systembegriff und Systemdenken in der Rechtswissenschaft).

El marcado escepticismo en torno a la posibilidad de «fundamentación» del Derecho proviene de varios flancos, pero sobre todo de las corrientes hermenéuticas y analíticas. En el plano de la Hermenéutica como disciplina de la comprensión de «sentidos» se lanza el llamado a tomar en cuenta no sólo el texto legal, sino también los aspectos subjetivos o vivenciales de quien interpreta. Este giro hacia el sujeto se vió, con seguridad, favorecido por la influencia, todavía perceptible en ese entonces, del Existencialismo (Jaspers, Scheler, Heidegger). La obra derrotera en esta dirección hermenéutica es, indudablemente, la de Josef Esser: Pre-concepción y elección del método en el proceso de encontrar el Derecho, 1970 (Vorverständnis und Methodenwahl in der Rechtsfindung), aunque ya Karl Engisch con su conocida tesis de que el acto de interpretar las normas jurídicas consiste en un «ir y venir de la mirada entre una premisa mayor (la ley) y los supuestos fácticos de la vida», se había adelantado a lo que se dirá después (partiendo de las influyentes ideas de Hans G. Gadamer, Verdad y Método = Wahrheit und Methode, 1960).

Por otro lado, en el plano de las corrientes analíticas surgen importantes investigaciones que después llegarían a convertirse en campos autónomos 
de estudio y que agudizan igualmente el escepticismo sobre el carácter de la ciencia jurídica. Todas estas investigaciones tienen en común un interés por la formalización del Derecho, acudiendo para ello a disciplinas como la Lógica, la Teoría de las ciencias, la Lingüística. Los trabajos pioneros de Engisch: Estudios lógicos en torno a la aplicación del Derecho, 1943 (Logische Studien zur Gesetzanwendung) y de Klug: Lógica jurídica, 1951 (Juristische Logik) ganarían en importancia. Se inicia aquí un extenso debate sobre dos cuestiones principales: sobre el grado de utilidad de la lógica en las discusiones jurídicas y sobre qué tipo de lógica es el que debe emplearse allí. Esta discusión se vió abonada considerablemente por las investigaciones en torno a la lógica deóntica (Weinberger, 1970; Rödig, 1972). En esta misma línea analítica surgirá, en segundo lugar, un gran interés por el esclarecimiento lingüístico de los conceptos jurídicos desarrollándose así importantes estudios en torno a los conceptos indeterminados, la vaguedad, la porosidad y la ambigüedad del lenguaje jurídico (el autor más representativo aquí es, sin duda, Hans J. Koch, 1976 y 1977). Una tercera línea de trabajo que se desarrolla en este plano está dada por la llamada «Wissenschaftstheorie der Rechtswissenschaft». De especial mención aquí son las reflexiones de Eike von Savigny o de Neumann (en: AA.VV. [1976]).

3. La tercera fase a la que he aludido está dominada por un regreso de la Teoría del Derecho al problema de la «fundamentación» normativa (que había sido prácticamente abandonado durante el segundo periodo). Este problema, que ya se encontraba presente y alcanzó su clímax en la época de postguerra, adquiere, sin embargo, en la actualidad un perfil muy diferente. Ahora no se trata de fundamentar las categorías jurídicas a partir de unos valores trascendentes, atemporales y ahistóricos, ni tampoco de encontrar unos valores inmanentes o derivados de la «naturaleza de las cosas», sino que se acude a otros criterios. Se trata aquí, pues, tal y como describe Neumann, de un intento de desarrollar una «ética jurídica sin metafísica» (en: AA.VV. [1994a], p. 179). La pregunta por el «Derecho correcto» (richtiges Recht), que era propia del movimiento neo-kantiano y en especial de Rudolf Stammler, vuelve a renacer con toda vitalidad, sólo que ahora con ropajes secularizados. Algunos actores importantes en esta nueva fase «eticisista» son, tal y como veremos de seguido, Horkheimer, Habermas, Adorno o incluso Ernst Bloch, pero también se asiste a una considerable influencia de los teóricos norteamericanos: John Rawls y Ronald Dworkin, así como de las denominadas «teorías jurídicas de la argumentación» (Atienza, 1997).

Los fundamentos teóricos de los que parte esta nueva fase ética los propicia la llamada «filosofía práctica». Es indudablemente dentro de este contexto que se ha experimentado en las últimas décadas un florecimiento sin 
igual en el ámbito de las teorías éticas (emotivismos, naturalismos, intuicionismos, corrientes analíticas, pragmáticas, utilitaristas, consecuencialistas, relativistas, etc.). Este renacimiento de las teorías axiológicas encuentra su origen en la toma de consciencia de un «estado espiritual» que agobia a muchas sociedades modernas y que se caracteriza por los siguientes rasgos: destrucción del medio ambiente, crecimiento poblacional, desigualdad masiva entre las formas de vida de los países «desarrollados» tecnológicamente y los países de la «periferia», la crisis del llamado Estado de bienestar, el complejo fenómeno de la «globalización» y de los grandes bloques económicos, los desarrollos revolucionarios de la genética, de la biotecnología y de la informática, el fénomeno de la migración de los países «del sur» hacia los países «del norte», entre otros muchos. Es indudable que detrás de muchos de estos conceptos y categorías se encuentran simples «fórmulas vacías» o términos semánticamente vacuos; sin embargo, este punto no está en discusión aquí. Lo importante por ahora es reconocer el transfondo socio-cultural que ha servido de fermento para que en el ámbito de la Filosofía y de la Teoría del Derecho hayan renacido nuevamente las discusiones en torno a la «justicia» y a la fundamentación normativo-ontológica del Derecho.

B. La segunda peculiaridad (a la que me referí en un inicio) que surge cuando se observa el desarrollo de la Teoría del Derecho en Alemania es la discusión en torno al concepto mismo de «Teoría del Derecho». Se trata aquí en lo fundamental de una discusión sobre palabras. No obstante, esta discusión puede tener alguna relevancia teórica (y de hecho la ha tenido), por ejemplo, para efectos de delimitación de competencias temáticas.

Si seguimos el esquema que he esbozado arriba, entonces se puede afirmar que el giro desde la «Filosofía del Derecho» hasta la «Teoría del Derecho» se verifica justamente una vez abandonada la fase metafísica a la que me he referido. Es decir, una vez que empezó a ponerse en tela de duda las formas de argumentación propias de la postguerra -basadas en el Derecho natural- entonces se inicia paralelamente un proceso de secularización y de «superación» de la filosofía y de su respectivo relevo por una «teoría» del fenómeno jurídico. No es entonces extraño que ya hacia los años setentas se funden en Alemania las dos revistas más influyentes en esta materia, me refiero a la «Rechtstheorie»y al «Jahrbuch für Rechtssoziologie und Rechtstheorie», y que además se observe desde ese momento una clara sustitución -o al menos un desplazamiento- del interés por la «filosofía» hacia la «teoría» del Derecho. Esta circunstancia se confirma también con la aparición de una serie de «manuales» con ese título (Kaufmann, 1971; Maihofer, 1971), lo que hasta ese momento era inusual. Es en este contexto donde se puede entender a cabalidad el diagnóstico ofrecido por Ralf Dreier en 1975: 
« ¿La Filosofía del Derecho ha muerto. Viva la Teoría del Derecho!» (Dreier, 1981, p. 17).

Al nacimiento de esta «teoría» está vinculado, por otra parte y tal y como se ha dicho, un claro escepticismo respecto a los argumentos de tipo ontológico o metafísico. Este escepticismo se encontraba indudablemente reafirmado por el creciente interés en la filosofía analítica y un dominio, en ese entonces, claramente perceptible de las corrientes asociadas al Neo-positivismo lógico (Carnap, Kraft, Schlick, Wittgenstein). Se acude, entonces, a un marcado desplazamiento desde las cuestiones de «fundamentación» hacia las cuestiones de «clarificación» del Derecho. Surge aquí la importante rama de estudio denominada: Derecho y lenguaje (Recht und Sprache) que en Alemania se convertiría también en objeto de importantes investigaciones (Eckmann, 1969; Oksaar, 1967; Koch, 1976), manteniéndose hasta la fecha como un atributo esencial de las corrientes analíticas.

En la actualidad se tiende a utilizar el término «Teoría del Derecho» para enfatizar el aspecto lógico-descriptivo de los fenómenos jurídicos (Rüthers, 1999, pp. 15 y ss.). La noción de «Filosofía del Derecho» se emplea tendencialmente para referirse a las cuestiones axiológicas (e.g. al problema de la «justicia»). Y finalmente, el concepto de «Sociología del Derecho» apunta a los problemás fácticos, o sea al tratamiento «empírico» del Derecho. Los límites son aquí, por supuesto, muy difusos y ello no puede ser de otra manera, ya que no existe una línea divisoria definitiva entre el ser y el deber. En otras palabras, no existe una realidad fuera de los valores al igual que tampoco existen unos valores-en-sí.

\section{Las orientaciones principales de la Teoría del Derecho en Alemania}

«Generalizar es ser idiota», sentenciaba drásticamente el poeta W. Blake. Pues bien, con el riesgo de sucumbir ante esta lapidaria máxima se puede afirmar que la Teoría actual del Derecho en Alemania se mueve en cuatro líneas básicas de trabajo. Para efectos de claridad se puede hablar entonces de los siguientes grupos de investigación:

1. Las corrientes de orientación sociológico-realista,

2. Las corrientes de orientación racional-discursiva,

3. Las corrientes de orientación sistémica y

4. Otras corrientes: Neo-institucionalismo, corrientes analíticas, retóricas, hermenéuticas, postmodernas, Análisis Económico del Derecho.

Esta clasificación, al igual que cualquier otra, tiene tan sólo un propósito heurístico, es decir, lograr claridad y apreciar con mayor facilidad el amplio espectro de opiniones existentes. Es posible que un autor se ubique dentro de una o más de las categorías indicadas o incluso que no se identifique con ninguna de ellas. Igualmente, es evidente que esta clasificación no 
tiene por qué cubrir toda la amplia gama de opiniones y de autores que circundan en el dinámico mundo de la Teoría del Derecho alemana. Toda clasificación está rodeada por zonas de penumbra y los límites entre una y otra categoría estan marcados por líneas claroscuras que son, por ello, siempre difusas y relativas. Además, y esto también es importante, cómo se realice una clasificación depende en gran medida de las pre-concepciones (por no decir prejuicios lógicos o existenciales) que marcan la actividad académica de quien hace dicha clasificación.

\section{Las corrientes de orientación sociológico-realista}

La tradición sociológica y realista del Derecho encuentra en Alemania un origen tempranero. Antes de que los «realismos» en sus vertientes norteamericanas o escandinavas lanzaran su manifiesto de regresar al Derecho real, tal y como éste se practicaba en los tribunales de justicia, o para decirlo con Pound, antes de que se diera el grito de volver al «Law in Action» y abandonar el «Law in the Books», dos autores alemanes ya habían levantado similares proclamas. Me refiero a OSKAR VON BÜLLOW y al «segundo» RUDOLF VON IHERING. Es a este último autor a quien se le suele atribuir la paternidad del espíritu realista alemán (e.g. Hierro, en: AA.VV. [1996], p.78). No obstante, con ello se le resta importancia a Büllow, quien en el año 1885 publicó su conocido escrito «Gesetz und Richteramt», convirtiéndose así en una excepción y un caso particular en el marco de la tradición idealista, dominante en esa época. Esta excepción fue, no obstante, poco menos que olvidada por la Teoría del Derecho. La idea central de Büllow consiste en afirmar que la ley determina en un grado muy escaso el contenido de las resoluciones de los jueces. El papel central en la construcción del Derecho lo ejerce el Juez. Es en la magistratura (en el «Richteramt») donde verdaderamente adquiere forma definitiva el texto legal. La ley una vez emitida por el legislador: «No es todavía Derecho vigente. Ella es tan sólo un plan, un proyecto del futuro ordenamiento jurídico al que se desea llegar...» (Büllow, 1972, p. 3).

Es claro que las corrientes sociológico-realistas tienen en Alemania una serie de entrefases importantes que permiten afirmar su presencia a través de la historia de la Teoría del Derecho. Dentro de estas entrefases se puede ubicar, por ejemplo, a la Jurisprudencia de Intereses o incluso a la Escuela del Derecho libre. Autores como Ehrlich, Kantorowicz, Heck, y Geiger son, indudablemente, teóricos en los cuales estuvo siempre presente el ánimo de entender el Derecho, más que como un fenómeno puramente normativo, como un «hecho social» real. Ahora bien, sin necesidad de regresar tanto tiempo atrás, la tradición sociológica y realista del Derecho se aprecia también con claridad en lo que hoy se podría denominar la «nueva Jurisprudencia 
sociológica», tal y como ésta es defendida por algunos sociólogos críticos del Derecho (Blankenburg, Opp, Röhl, Raiser, véase en especial Rehbinder, 2000, pp. 8-30). Para este último autor, dicha Jurisprudencia se encarga no sólo del estudio empírico de la aplicación del Derecho, sino también del estudio de su creación y es en este sentido una forma de «política jurídica». «Como toda política, ésta se pregunta y busca resolver cuáles metas sociales pueden alcanzarse con ciertos mecanismos jurídicos» y es en ese tanto, al igual que la política, «el arte de lo posible» (Rehbinder, 2000, p. 26). Igualmente, la denominada «Rechtstatsachenforschung» (Investigación de los hechos jurídicos) constituye un crisol importante en el cual se conjugan una serie de investigaciones empíricas del Derecho de corte muy crítico (véase Heinz, 1998). Esta corriente encuentra, sin embargo, su asidero principal en el Derecho civil y no así en las otras ramas jurídicas.

Una exigencia central que puede rastrearse en todas las corrientes realistas del Derecho es la del trabajo conjunto entre las ciencias jurídicas y otras disciplinas empíricas (Sociología, Criminología, Psicología, Medicina, etc.). Esta relación interdisciplinaria se ha mostrado a la fecha altamente problemática. De allí que en la actualidad se ha caído en un estado de resignación y pesimismo según el cual el diálogo entre la ciencia jurídica (como disciplina normativa) y otras disciplinas empíricas es poco menos que imposible. En este contexto existe un aspecto que no ha sido suficientemente estudiado, pero que, desde mi punto de vista, puede ser muy esclarecedor en el acto de visualizar las posibilidades y los límites del trabajo interdisciplinario entre el Derecho y las ciencias reales. Se trata de lo siguiente:

Tal y como se verá después, una de las principales preocupaciones de la actual Metodología Jurídica consiste en determinar aquellas formas de argumentación propias del discurso jurídico, para así poder fundamentar de una forma más «racional»o «razonable» las decisiones (sentencias) que se tomen en la práctica judicial. Este es el propósito principal, por ejemplo, de la llamada «teoría de la argumentación jurídica», tan en boga en la actualidad. Detrás de esta tesis reposa, si se mira con atención, la idea de que en la disciplina jurídica existe una forma específica de argumentar o unos métodos sui generis, los cuales si se emplean bien entonces podrían generar mejores sentencias, es decir, una praxis jurídica más racional y bien fundamentada.

Las preguntas claves que hay que plantearse en este contexto son, sin embargo, las siguientes: ¿Está justificada tal idea? ¿Existe verdaderamente una forma específica de «argumentación jurídica»? ¿Existen unos métodos que puedan garantizar resultados racionales? ¿O se trata aquí de una esperanza cuyo origen reposa en un «conocimiento cotidiano» de la realidad (en 
eso que los alemanes llaman una «Alltagstheorie»)? Es justamente en dar respuesta a estas interrogantes donde el análisis sociológico-realista puede ser de mucha utilidad.

Sin pretender dar respuesta a estas cuestiones, me gustaría simplemente referir al hecho de que sobre tales problemas existe en Alemania una larga tradición que se remonta hasta los años 70s con la llamada «Richtersoziologie» (Sociología de/sobre los jueces) y posteriormente con la «Soziologie der Justiz» (Sociología sobre la impartición de justicia). Durante esta época se realizaron una serie de estudios empíricos, algunos de ellos muy rigurosos, cuyo propósito central era, entre otros, determinar las formas específicas de argumentación (si es que existían) que utilizaban los jueces -y ocasionalmente también otros operadores jurídicos- en la vida judicial práctica. A título de ejemplo, me gustaría citar los siguientes trabajos: Wolfgang Kaupen, Die Hüter von Recht und Ordnung (Los guardianes del Derecho y el orden, 1969), Walter Weyrauch, Zum Gesellschaftsbild der Juristen (Sobre la imagen del mundo de los juristas, 1970), Rüdiger Lautmann, Justiz - die stille Gewalt-. (La justicia -una forma callada de poder-, 1970), K.D. Opp/R. Peukert, Ideologie und Fakten in der Rechtsprechung (La ideología y los hechos en la jurisprudencia, 1971), Dorothee Peters, Richter im Dienst der Macht (Los jueces al servicio del poder, 1973), entre otros muchos.

Sin pretender resumir los resultados de estos interesantes estudios se puede decir, a modo muy general, que la conclusión a que ellos llegan es la siguiente:

La actividad de los operadores jurídicos (de los jueces en especial) es una actividad muy compleja que está influida por una enorme variedad de factores (objetivos, subjetivos, jurídicos, metajurídicos, racionales, emotivos, etc.). No existe detrás de dicha actividad una forma específica de argumentación, ni tampoco unos métodos particulares, sui generis (¡y mucho menos «universales»!), que puedan emplearse en todos los procesos de decisión judicial.

Ahora bien, cabe entonces preguntarse dos cosas importantes: (1) ¿Qué sucedió con estos estudios, es decir, cuál fue su influencia? y, (2) ¿Fueron esas investigaciones consideradas a lo interno de la Metodología Jurídica o de la Teoría del Derecho?

Respecto a la primera pregunta hay que indicar que los estudios en cuestión tuvieron poca o ninguna repercusión. En muchos casos se consideró más bien que sus autores incurrían en abiertas «difamaciones y calumnias» en contra de los funcionarios judiciales (véase Rehbinder, 2000, p. 162), y en otros casos los estudios fueron simplemente olvidados. Respecto a la segunda pregunta, también hay que contestarla negativamente. Ni la Metodología Jurídica ni la Teoría del Derecho tomaron nota en serio de las conclusiones a las que allí se llegó y a consecuencia de ello es que a la fecha se 
continúa buscando una forma particular de fundamentación judicial, o dicho con lenguaje moderno, se continúa buscando una «teoría de la argumentación» o unos métodos correctos para trabajar con el Derecho. Tales intentos parecen estar destinados a surtir pocos efectos en la práctica jurídica real, pero en el plano puramente teórico-cognoscitivo sus resultados pueden ser, para algunos teóricos, interesantes. Existe, sin embargo, un aspecto que hoy día es generalmente reconocido y que tuvo su origen en la discusión en torno a los estudios citados. Se trata de la idea de que es absolutamente necesario distinguir entre dos fenómenos: entre los motivos o causas de una decision (judicial), por una parte, y la fundamentación de esas decisiones, por la otra. Un juez puede tener motivos perversos y aun así dictar sentencias adecuadas, justas y apegadas perfectamente a la normativa vigente, es decir, bien fundamentadas.

A lo interno de la tradición sociológico-realista actual me gustaría mencionar a tres autores que pueden considerarse como abanderados de dicha tradición en la actualidad. Me refiero a: Hans Albert, Bernd Rüthers y Klaus Röhl. Todos ellos trabajan en líneas de investigación muy diferentes, pero están unidos por un lazo común: su deseo de entender el Derecho, más que como una disciplina eminentemente normativa, como un fenómeno social real altamente complejo.

HANS ALBERT es un caso especial dentro de la Teoría del Derecho pues su núcleo de interés no reposa específicamente en esa rama. A pesar de esta circunstancia su influencia es importante. Ello se debe, quizás, a que por encontrarse al margen de la discusión propiamente jurídico-dogmática ha logrado conjugar los puntos de vista que allí se manejan con ideas de otros campos, especialmente con ideas del Racionalismo Crítico, de la Sociología y de la Economía política, logrando así una visión muy rica en matices.

Las ideas centrales de Albert en materia de Teoría del Derecho se concentran, desde mi punto de vista, en dos direcciones muy concretas:

a. Por un lado, en una crítica de lo que él denomina la Jurisprudencica pura y

b. Por otro lado, en su propuesta de una Jurisprudencia social-tecnológica.

Respecto al primer punto debe indicarse que Albert entiende la noción de «Jurisprudencia pura» en un sentido amplio (Albert, 1992, pp. 347 y ss.). Se trata aquí de la tradicional caracterización del Derecho como una disciplina meramente dogmática y normativa. Dos de las principales objeciones que esgrime Albert contra una disciplina del Derecho así conceptualizada son las siguientes: ella tiene que renunciar a la idea de verdad, por un lado; y por otro lado, prescindir de un estudio de los efectos reales perseguidos 
por normas. Con la renuncia a estas dos dimensiones, la ciencia jurídica degenera en un «platonismo-de-las-normas» (Albert, 1993, pp. 12 y ss.), es decir, en una concepción que analiza las disposiciones jurídicas no como hechos sociales sino como si éstas tuvieran una existencia propia e independiente de los efectos que quieren alcanzar. El resultado final de un enfoque semejante es, según Albert, la renuncia definitiva al conocimiento y su sustitución por un saber «autoritario» (en el sentido de que se basa en determinadas autoridades como: la doctrina dominante, la jurisprudencia de los tribunales superiores, ciertos autores conocidos, etc.).

En lo atinente al segundo punto, es decir, a la propuesta de una Jurisprudencia social-tecnológica, Albert reconoce que esa idea no es del todo nueva, pues ya se encuentran elementos parecidos en los trabajos de Ross y mucho antes que él en las tesis de la filosofía social escocesa y particularmente en Hobbes (Albert, 1992, p. 354). En la elaboración de su propuesta social-tecnológica Albert parte de dos postulados ontológicos que son también centrales para el Racionalismo Crítico, a saber, las tesis de que:

a. Existe una realidad, y que

b. Sobre esta realidad es posible emitir enunciados verdaderos o falsos.

En un primer momento, pareciera que se trata aquí de aseveraciones de perogrullo las cuales incluso no es necesario efectuar por evidentes. Una opinión tal sería incorrecta. La defensa del Realismo que emprende Albert en el ámbito de la Jurisprudencia es una defensa que ya se había dado en el campo propiamente filosófico y cuyo principal artífice, junto a Albert, fue precisamente Karl Popper. La importancia capital de la defensa del Realismo (es decir, de la idea de que existe una realidad objetiva más allá de nuestra propia consciencia) sólo se comprende a plenitud si se tienen en mente las múltiples corrientes modernas que han puesto en duda, muchas veces de forma subrepticia, esta tesis. Debe pensarse aquí no sólo en corrientes y autores «clásicos» contra los cuales ya se había enfrentado Popper (Berkeley, Hume, Kant), sino en concepciones mucho más actuales que también apuntan en esa misma línea (e.g. el llamado «constructivismo cognitivo» = Bateson, Ernst von Glasersfeld, Heinz von Foerster, Maturana, Luhmann o incluso autores como Habermas y Apel). En todos estos casos, la realidad y su conocimiento se transforman en un asunto de «estructuras», de «comunicación», de «consenso», etc.

Es importante indicar que el Realismo del que parte Albert es de naturaleza crítica. De allí que la forma en que él conceptúa la realidad guarda una importante diferencia respecto a la forma como lo hace el Racionalismo clásico. En éste se aspira a una fundamentación «última» de los fenómenos. A este tipo de fundamentación le denomina Albert el «punto arquimédico del conocimiento» (1991, capítulo 1). Una vez que esa fundamen- 
ción se ha logrado, entonces, según la opinión de los racionalistas clásicos, se ha alcanzado también la «verdad». Como refutación a esta idea es que Albert formula una de sus categorías más conocidas, a saber: el llamado «Trilema de Münchhausen». Con este «Trilema» lo que pretende demostrar Albert es que cualquier enfoque que aspire a una fundamentación definitiva y última del saber humano (a un principium rationis sufficientis) conduce necesariamente a un callejón sin salida. El Trilema en cuestión se puede plantear de la siguiente forma:

1. Toda derivación lógica de un enunciado exige retrotraerse hasta otro enunciado anterior, el cual a su vez requiere ser derivado también de otro enunciado previo a él mismo, de manera que el proceso de fundamentación cae inevitablemente en una regresión ad infinitum.

2. Se puede acudir a enunciados que en sí mismos no pueden ser demostrados sino tan sólo afirmados, pero entonces se cae en un círculo vicioso.

3. El proceso de fundamentación se tiene que romper recurriéndose al carácter auto-evidente de los enunciados, es decir a la experiencia o a la valoración, a la autoridad o al consenso (Albert, 1991, p. 15).

En el ámbito de la Jurisprudencia el Realismo crítico de Albert se manifiesta fundamentalmente en la forma de conceptualizar las normas jurídicas. Albert reconoce como posible que las normas sean objeto de estudios lingüísticos (filosofía analítica), de estudios sobre el sentido (Hermenéutica Jurídica), de estudios sobre correlaciones semánticas (Lógica Jurídica), etc.; sin embargo, lo característico de las normas jurídicas es que ellas están destinadas a surtir determinados efectos en una realidad social. El análisis de estos efectos (Analyse der Wirkungszusammenhänge) constituye el atributo central de una Jurisprudencia realista y social-tecnológica. De allí que Albert define una «tecnología» como un conjunto de enunciados sobre las «distintas posibilidades de acción, obtenidas éstas a su vez de otros enunciados que versan sobre correlaciones reales o causales. Los enunciados tecnológicos responden a la pregunta: ¿Qué se puede hacer para alcanzar determinadas finalidades»? (Albert, 1993, p. 12).

La segunda idea importante para Albert es, como ya se dijo, rehabilitar la idea de verdad dentro del ámbito de la Jurisprudencia. La idea de verdad se vincula en este contexto con la idea de «vigencia fáctica» de la normas jurídicas. Este último concepto se remite, por su parte, a la noción de «voluntad del legislador», la cual se entiende en un sentido objetivo; a saber, como un «querer» orientado a producir en los destinatarios de la normas ciertos efectos, o sea a generar ciertas formas de comportamiento social. Se logra así reducir el deber (Sollen) a un querer (Wollen), evitándose por ende incurrir en la disputa en torno al carácter axiológico de la norma. La noción de vigencia fáctica pasa a ser entendida como un «hecho social» de for- 
ma que las afirmaciones que se hagan en torno a ella tengan una naturaleza cognitiva y, por ende, susceptibles de calificarse como verdaderas o falsas.

El segundo autor al que me quiero referir en el marco de las corrientes sociológico-realistas de la actual Teoría del Derecho alemana es a BERND RÜTHERS. Este autor es ya muy conocido en el ámbito germano por su severa crítica a las teorías tradicionales de la interpretación jurídica, así como por su erudito conocimiento de las «perversiones» sufridas en el ordenamiento jurídico durante la época Nazi. Bernd Rüthers se basa para su crítica, no tanto en las ideas aportadas directamente por la Sociología jurídica, sino más bien en la Historia del Derecho. Es precisamente a través de un detallado estudio historiográfico y de la realidad judicial como Rüthers (Juez durante muchos años) se encarga de desmitificar uno a uno muchos de los conceptos de la Teoría y de la Metodología Jurídica. Es a través de obras como: Lo injusto de la justicia (Das ungerechte an der Gerechtigkeit, 1993), La interpretación sin límites (Die unbegrenzte Auslegung, 1997), Derecho Degenerado (Entartetes Recht, 1989), Ordenamiento Jurídico y Ordenamiento Valorativo (Rechtsordnung und Wertordnung, 1986), entre otras, donde Rüthers demuestra, mediante una cantidad considerable de ejemplos y de sentencias, cómo los juristas alemanes han podido llegar a teorías y a resoluciones absolutamente contrapuestas partiendo de idénticas disposiciones jurídicas. Una de las críticas recurrentes de Rüthers es el hecho de que en Alemania hayan existido entre 1910 y 1990 cinco $(i i)$ sistemas políticos o formas de gobierno radicalmente diferentes y que en todos ellos los juristas se hayan valido, sin mayores reparos, de las mismas leyes y códigos para fundamentar sus fallos.

La última obra de Rüthers, su «Rechtstheorie» es donde el autor plasma en una forma clara y concreta sus tesis principales. Toda la obra está marcada, desde mi punto de vista, por dos ideas centrales, a saber:

- La idea de que el Derecho es un producto de la sociedad, de las ideologías y de las estructuras de poder (de allí que se incluyan apartados como: «Poder estatal y Derecho», «Clase y Derecho», «Raza y Derecho»). En todos estos apartados Bernd Rüthers se esfuerza por ilustrar, de forma sencilla y con ejemplos tomados de la práctica jurídica real, por qué muchos de los conceptos claves de la Teoría del Derecho contemporánea (tales como: «argumentación», «razón», «discurso», «comunicación», «racionalidad», «ciencia», etc.) deben ser interpretados a la luz de una concepción realista para no incurrir así en ilusiones y mistificaciones de la teoría y de la práctica jurídica. Así señala Rüthers, por ejemplo: « En la solución de problemas normativos se requieren siempre compromisos, ello si se desea que el Estado constitucional, democrático y liberal sobreviva. Tales compromisos 
no son, sin embargo, un producto de la razón científica, sino de los acuerdos sociales» (1999, p. 349).

- Una segunda idea central en Rüthers tiene que ver con el papel preponderante que él asigna a la actividad de los jueces (Richterrecht) y en la crítica que efectúa al respecto. Mediante el estudio de la realidad judicial en distintas épocas históricas, Rüthers demuestra cómo los jueces juegan un papel importantísimo en la creación y configuración del ordemiento jurídico. De allí que, valiéndose de una gran cantidad de ejemplos, denomina a los jueces como los «legisladores substitutos» del sistema jurídico (Rüthers, 1999, p. 137).

Otro autor de una orientación declaradamente sociológico-realista es KLAUS RÖHL. Las obras más importantes de este autor son sus dos manuales de: «Rechtssoziologie» (Sociología jurídica, 1987) y su reciente «Allgemeine Rechtslehre» (Teoría General del Derecho, 2001). Esta última, se trata de una obra comprensiva (660 páginas) que trae a discusión la mayoría de autores y corrientes importantes a lo interno de la Teoría del Derecho. El análisis que realiza Röhl de todas las categorías básicas del Derecho se caracteriza por una particular agudeza y sentido crítico. Es así como él considera, por ejemplo, que una de las funciones principales de la Teoría General del Derecho consiste en «sacar a relucir todas las irracionalidades propias del razonamiento jurídico» (Röhl, 2001, página 7).

Algunos otros autores relativamente «jóvenes» que muestran rasgos o afinidades con las corrientes realistas son, por ejemplo, ERIC HILGENDORF (1991) o H. KEUTH (1993) etc.; sin embargo, habrá que dar tiempo para apreciar mejor en qué dirección se desarrollan sus tesis.

\section{Las corrientes de orientación racional-discursiva}

La discusión en torno al papel que juega la «razón» (prescindiendo de los múltiples significados, incluso emotivos, de esta palabra) en el Derecho ha sido desde tiempos inmemoriales un tema controversial. Testimonio de ello es la larga tradición histórica que existe en Alemania sobre el llamado «Vernunftrecht» (Derecho de la Razón) y cuyo principal punto de referencia lo constituyen indudablemente los distintos bandos del Racionalismo clásico y del Idealismo en sus distintas manifestaciones. La raíces de esta tradición se encuentran desde antiguo en autores como Grocio, Pufendorf, Tomasius o Christian Wolff y, por supuesto, en Kant y Hegel.

Sin embargo, no es necesario retrotraerse hasta estos tiempos remotos para experimentar en todo su vigor la importancia que la categoría de «razón» tiene en la Teoría del Derecho alemana. No. La historia también procrea hijos fieles. En la actualidad es posible encontrar un nuevo «Vernunftrecht». Este Derecho de la razón contemporáneo se caracteriza, al igual que 
su predecesor, por la insistencia -y acaso la esperanza- de que la actividad jurídica sea una actividad fundamentalmente de tipo «racional». La diferencia radica en que la razón -a contrapelo de lo que sucedía en el pasadono es ya una razón absoluta y trascendental en el abigarrado estilo de Hegel, Fichte o Schelling («Realität ist Idealität»), sino que ahora se ha desplegado, retomando la herencia kantiana y neokantiana, en una «Razón Práctica». Qué se tiene que entender exactamente bajo ese concepto no resulta siempre claro, pues él es empleado, no con poca frecuencia, en un sentido persuasivo y apelando muy genéricamente al binomio kantiano entre razón práctica/razón pura. Según este binomio, correspondería al segundo tipo de razón la explicación de las condiciones de posibilidad del saber humano, mientras que al primer tipo compete ofrecer los argumentos «prácticos» para la acción moral o jurídica. La segunda ecuación del binomio trata, pues, de responder a la pregunta: ¿qué puedo saber?, mientras que la primera, a la interrogante: ¿qué debo hacer?

Lo cierto del caso es que algunos autores contemporáneos consideran a la razón práctica como uno de los conceptos fundamentales de la Teoría del Derecho. Así, por ejemplo, KRIELE sostiene que «la totalidad del Derecho está dominado por ponderaciones racionales» (1976, p. 227). Este autor estima entonces como necesaria una «rehabilitación de la razón práctica», la cual él pretende llevar a cabo a partir, entre otras cosas, de los conceptos de «sciencia» $\mathrm{y}$ «prudentia», limitando el primero al ámbito de las disciplinas naturales y el segundo al de las disciplinas de la conducta, y considerando a su vez como un gravísimo error del pensamiento jurídico contemporáneo haber convertido a la Jurisprudencia en una «Juris-scientia» (Kriele, 1979, p. 17 y ss.). La tesis central de quienes defienden la idea de la razón práctica la resume Kriele de la siguiente forma: «Los juicios prácticos son posibles de fundamentar racionalmente» (1979, p. 19). El principal instrumento de que se vale el jurista en este proceso es la «argumentación». Esto nos lleva a otro autor, quien goza de una amplia popularidad en la Teoría actual del Derecho y que desarrolla en detalle esta misma línea de trabajo; me refiero a Robert Alexy.

ALEXY considera posible elaborar, tal y como él mismo lo indica, un «codigo de la razón práctica», el cual constituiría «el resumen y la formulación explícita de...las reglas y formas de argumentación racional-práctica» (Alexy, 1991, p. 234). De allí que para Alexy el Derecho no es más que un «caso especial del discurso práctico general». Sobre esta idea, conocida como la «Sonderfallthese» (tesis del caso especial) se ha originado un gran debate en la Teoría del Derecho alemana (véase e.g. Alexy, 1991, p. 426 y ss.). El proyecto de Alexy en materia jurídica es más que ambicioso, pues después de efectuar una crítica atinada y de gran claridad a algunas corrientes 
de la filosofía moral (Naturalismo, Intuicionismo, Emotivismo, Constructivismo, etc.) se da a la tarea de explicitar las «reglas del discurso práctico» (Alexy, 1991, pp. 221-257). Estas reglas se dividen, según él, en distintos subgrupos. Por un lado, están las «reglas básicas» (Grundregeln) que tienen que respetarse en todo discurso racional: ningún locutor ha de contradecirse, todo locutor tiene que expresar únicamente aquello en lo que cree, todo locutor que aplique un predicado $\mathrm{F}$ a un cierto objeto debe estar preparado para aplicar ese predicado a objetos similares, y, por último, los locutores no deben emplear sus expresiones con sentidos diferentes. Posteriormente, Alexy explica otros subgrupos de reglas importantes, dentro de las cuales están las «reglas de la razón» propiamente (Vernunftregeln), las «reglas en la carga de la argumentación» (Argumentationslastregeln), las «reglas de fundamentación» (Begründungsregeln) y, finalmente, las «reglas de transferencia» (Übergangsregeln).

La concepción de Alexy ha recibido internacionalmente y desde su formulación en 1978 un amplio reconocimiento. Es precisamente con su obra que se desata en Alemania una discusión en torno a las Teorías de la Argumentación que hoy día es prácticamente inabarcable. Ella ha dominado durante los últimos años una gran parte del territorio concedido por las revistas especializadas (por ejemplo, por la «Rechtstheorie»). Una particularidad de esta corriente es el interés que han demostrado, no tanto los teóricos alemanes, sino más bien muchos extranjeros (Aarnio, Toulmin, Perelman, MacCormick, Wróblewski, Peczenik, Pavcnik, Raz, Atienza, etc.).

Un autor, quien igualmente se puede ubicar dentro de la línea de las teorías «racionales» del Derecho, es OTFRIED HÖFFE, pues oficialmente se le considera como uno de los neo-kantianos más importantes en Alemania actualmente. El núcleo principal de investigación de este autor reposa en la filosofía política (aunque su producción en otros campos es también considerable). En una de sus recientes obras, titulada justamente Razón y Derecho. Fundamentos de un discurso jurídico intercultural, 1996 (Vernunft und Recht. Bausteine zu einem interkulturellen Rechtsdiskurs) busca Höffe hacer extensiva la categoría de «razón» incluso al ámbito del Derecho internacional. Höffe considera que la «razón jurídica» se compone en lo esencial de tres componentes: en la regularidad del Derecho, en la posibilidad de interponer una sanción y en el ejercicio de un poder judicial público (öffentliche Gewalt) que sea subsidiario e imparcial (1996, p. 41). Esta «razón jurídica» lleva al autor a postular algunos principios que considera esenciales para el discurso jurídico, dentro de los cuales están: el principio de subsidiaridad (Subsidiaritätsprinzip) y el principio de democracia (Demokratieprinzip). Ambas ideas conducen a Höffe a postular la existencia de unos «intereses trascendentales» que actúan como condiciones de posibilidad de 
la convivencia y de la acción humanas y que, finalmente, se trasladan al Derecho internacional (1996, S. 117 y ss.).

Sin embargo, el verdadero artífice y demiurgo del nuevo «Vernunftrecht» en Alemania es, sin lugar a dudas, JÜRGEN HABERMAS -canonizado ya por sus seguidores y excomulgado por sus oponentes- pero siempre presente en casi todas las discusiones actuales sobre Teoría del Derecho. Una prueba de esta gran influencia está dada por la circunstancia de que en el momento en que el suscrito redacta estas líneas, Habermas recién recibe unos de los galardones más importantes otorgados en el mundo académico e intelectual alemán: el «Friedenspreis des deutschen Buchhandels».

El Caso-Habermas es un caso especial dentro de la Teoría del Derecho, pues sus intereses en una primera etapa giraban tan sólo muy indirectamente en torno a este campo. Recuérdese que durante los años 60 s y 70s -que es cuando Habermas inicia su curriculum académico en el seno de la Escuela de Frankfurt- dominaba por completo en los círculos críticos y de izquierda una atmósfera neo-marxista dentro de la cual el Derecho no era sino un elemento secundario, «super-estructural», de las relaciones de producción capitalistas. Es hasta en una fase más reciente, y a partir de la publicación de su «Faktizität und Geltung» (1992), donde Habermas inicia lo que podría llamarse su «fase jurídica» en sentido estricto. A pesar de esta circunstancia, el lenguaje habermasiano se ha extendido rápidamente en los círculos de la Teoría del Derecho hasta el punto de que es difícil tomar un texto, monografía, revista o manual de esa disciplina sin encontrarse conceptos como: discurso, consenso, agente, situación ideal del habla, comunicación, pragmática trascendental, etc.

Las bondades que ofrecen autores como Habermas, Alexy o Luhmann (del que me ocuparé posteriormente) es que otorgan al mundo académico ciertos conceptos-estandarte que parecen resultar de mucha utilidad en algunas discusiones académicas. Lo paradójico del caso es que esta circunstancia se revierte finalmente contra el propio autor y en grave detrimento de sus propias concepciones, pues sus categorías «técnicas» son empleadas a posteriori con toda laxitud. La vaguedad terminológica siembra así las semillas de su propia auto-destrucción.

El núcleo, y lo que quizás hace tan atractiva para muchos la concepción de Habermas, radica, desde mi punto de vista, en dos aspectos centrales:

a. En la posibilidad de fundamentar los juicios normativos o de valor y

b. En la posibilidad de «comunicación» humana.

Respecto al primer punto, Habermas se identifica parcialmente con todas las teorías morales cognitivistas que existen desde muy antiguo, empezando por las diversas orientaciones del Derecho natural y llegando hasta el intuicionismo y el naturalismo éticos. Lo fundamental aquí es la idea de que 
los juicios morales son posibles de fundamentar en un sentido similar a como se hace con los postulados empíricos (Habermas, 1973, p. 242 y ss., 252 y ss.). Se establece entonces el siguiente paralelismo básico: la verdad es a los enunciados empíricos lo que la «corrección» (Richtigkeit) es a los juicios axiológicos. Respecto a esta posibilidad es que se dió en Alemania, durante los años 60s, la conocida polémica Habermas-Albert, la cual vendría a marcar el ritmo de la discusión sociológica y metodológica durante muchos años (en: AA.VV. [1969]).

En lo que se refiere a la comunicación (o al «kommunikatives Handeln»), es donde Habermas, valiéndose de la noción de «Discurso», ha logrado su mayor éxito. Es a partir de allí donde deriva, por ejemplo, su teoría consensual de la verdad. Se abandona aquí, por insatisfactoria, la teoría clásica de la verdad por correspondencia y se establece en su lugar la noción de «consenso». La verdad es el producto del discurso. Pero, para que sea posible alcanzar a través del discurso enunciados de verdad es necesario que éste se lleve a cabo en unas condiciones especiales. A estas condiciones pertenece, por ejemplo, la «situación ideal del habla» así como unos «agentes de comunicación» dispuestos a seguir ciertas reglas (al respecto, muy crítico: Haba, 1996).

El núcleo de las tesis de Habermas no es original. Ideas parecidas se encuentran ya desde muy antiguo, por ejemplo en el método dialéctico de Sócrates. Por otra parte, resulta comprensible la popularidad que han ganado hoy día esas tesis. Particularmente, si se tiene presente que los seres humanos, tal y como afirmaba Kantorowicz, estamos inmersos en el «poder vivificante de la ilusión». La idea de comunicación que nos promete Habermas se corresponde en el plano espiritual con el «ordre $d u$ cœur» al que se refería Pascal, es decir, con un cierto orden místico del corazón humano, donde subyace siempre una necesidad profunda de que lo «verdadero» esté más allá de este mundo. Pero en el plano científico y específicamente socio-antropológico, las tesis habermasianas resultan incomprensibles, en especial si se tienen en mente las enormes dificultades y contingencias que suelen presentarse en los procesos reales de la comunicación humana. El acuerdo, pero sobre todo el «consenso» al que apunta el filósofo de Frankfurt, es un asunto que respecto a temas centrales del Derecho (la «justicia», la «igualdad», la «libertad») resulta simplemente imposible de alcanzar o en su defecto puede lograrse sólo en forma muy limitada y precaria.

En la misma línea de trabajo, pero con mucho menor repercusión entre los juristas, se encuentran las concepciones, ya hoy poco discutidas, de autores como K.-O. APEL, WOLFGANG KUHLMANN, LORENZEN y KAMLAH. Apel se concentra esencialmente en una fundamentación «pragmático-trascendental» del discurso. Con ello se apunta, en el sentido kan- 
tiano, a la idea de que existen ciertas reglas lingüísticas (pragmáticas) que constituyen las condiciones de posibilidad (trascendentales) de todo discurso. Los dos últimos autores se ubican dentro del llamado «Constructismo de la Escuela de Erlanger», trabajando en especial en el nivel lingüístico y considerando la verdad como un problema de «reconocimiento».

Todos los autores hasta ahora referidos tienen el rasgo común de que sus concepciones se encuentran en un nivel meta-jurídico o sociológico. Hay algunos otros teóricos que buscan, en un nivel más estrictamente jurídicodogmático, fundamentar sus teorías acudiendo, no obstante, a un arsenal metodológico similar. Este es el caso de autores como: Karl Larenz, W. Canaris, Pawlowski, Zippelius, etc. Algunos de ellos se pueden ubicar dentro de la llamada Jurisprudencia de Valores (Wertungsjurisprudenz) que se considera hoy día por algunos como la orientación dominante en materia de Metodología Jurídica (en especial en el campo del Derecho civil, véase Bydlinski, 1991, p. 123 y ss.), pero que, según mi opinión, representa más bien una actitud hacia la metodología y no tanto una teoría con rasgos concretos que se pueda adscribir a unos autores específicos.

En forma muy esquemática se puede decir, sin embargo, que la Jurisprudencia de Valores constituye, en términos generales, un intento de superación de la Jurisprudencia de Intereses. En contra de esta última, se solían esgrimir dos objeciones principales: Por una lado, que ella reducía el Derecho a un materialismo unilateral, pues al sólo considerar los «intereses» dejaba por fuera la esfera de los valores. Por otro lado, se le criticaba la enorme ambigüedad del concepto de «interés». Es como un intento de superación de estas objeciones, en especial de la primera, que surge la Jurisprudencia de Valores. En cuanto a la segunda objeción el resultado no es, como puede apreciarse, del todo satisfactorio, pues se sustituye la vaga noción de «interés» por otra aún más oscura: la de «valor».

La pregunta central que ocupa a la nueva Jurisprudencia de Valores se puede plantear (siguiendo a Bydlinski, 1991, p. 128) de la siguiente forma: ¿De dónde se derivan los criterios de valor que hay que emplear en caso de que la ley no regule el supuesto fáctico en cuestión? o con otras palabras: ¿De dónde provienen los valores que guían al juez en su actividad en caso de lagunas normativas? ¿Parte el Juez aquí de sus convicciones personales o existen otros criterios objetivos a los que él puede recurrir? A título de ejemplo me gustaría discutir, seguidamente, algunas tesis de los dos metodólogos que se consideran (por algunos) como los más importantes en Alemania.

Ante estas interrogantes KARL LARENZ, considerado el principal representante de la Jurisprudencia de Valores, acude a la ayuda de unos «criterios teleológico-objetivos» del Derecho. Así señala el autor: «Las finali- 
dades que busca realizar el legislador a través de las leyes son en muchos casos, por no decir en todos, finalidades objetivas...» (Larenz, 1991, p. 333). Es precisamente a la determinación y realización de estas finalidades a las que debe aspirar el operador jurídico por medio de su actividad interpretativa. En caso de lagunas normativas éstas deben ser «llenadas» acudiendo a estos valores objetivos que están presentes en el ordenamiento jurídico. Larenz distingue dos tipos de criterios objetivos: por un lado, ciertas «estructuras objetivas» o «circunstancias fácticas» de la vida que deben ser respetadas por el legislador; y por otro lado, unos «criterios ético-jurídicos» que están presentes detrás de toda regulación y cuyo punto de referencia final es la «Idea del Derecho» (la llamada «Rechtsidee», véase Larenz, 1991, p. 333). Dentro de estos criterios objetivos se pueden mencionar, por ejemplo, la «idea de justicia» o el «principio de igualdad» (Larenz, 1991, p. 334).

Es claro que el alcance semántico de los conceptos utilizados por Larenz es poco preciso. Qué debe entenderse por nociones como «objetivo», «principios-ético-jurídicos», «Idea del Derecho», etc. es una cuestión sujeta a debate. Pero en todo caso, aquí no es el lugar para realizar un crítica detallada de estas ideas. Me gustaría, no obstante, transcribir al respecto la opinión de otro importante téorico: «Quien apele a la Idea del Derecho, a los principios-ético-jurídicos, a la justicia u otras categorías similares, como si éstas fueran fuentes normativas, no apunta con ello a 'la' Idea del Derecho o a 'la' justicia, etc., sino más bien a su idea del Derecho, a su justicia. La argumentación que se lleva a cabo mediante tales nociones no significa otra cosa que el empleo de conceptos subjetivos o transmitidos por vías político-jurídicas y que pretenden falsamente tener una válidez científica demostrada. El conjuro que se lleva a cabo, sea mediante la 'fuerza milagrosa de la varita mágica llamada Idea del Derecho’ o mediante otras categorías -igual de sublimes pero poco precisas-, no contribuye en lo más mínimo a la solución racional de los problemas de la implementación del Derecho por parte de los juece» (Rüthers, 1999, pp. 502-503).

El segundo autor que quiero mencionar es PAWLOWSKI, cuyas obras principales se encuentran en el ámbito de la Metodología Jurídica (1986, 1991). En su manual sobre esta materia desarrolla el autor lo que pretende ser una teoría de la norma, una teoría de la ley y una teoría de la dogmática jurídica. Una categoría central que marca su obra desde principio a fin es la categoría de «corrección» (véase tan sólo el prólogo a la obra de 1991). Así declara Pawlowski, por ejemplo, que el Derecho está llamado a poseer un «método correcto» (1991, p. 5), que las leyes deben y pueden ser «correctas» (1991, pp. 44, 258), que existe una «interpretación correcta» (1991, pp. 171, 307), que puede haber una «dogmática correcta» (1991, p. 316), que existen las «decisiones correctas» (1991, p. 174), etc. Indudablemente que 
esta insistencia del autor dificulta mucho seguir las tesis que expone (al menos para aquellos que no somos tan optimistas respecto a la «corrección» del Derecho y su «ciencia»). Además de que Pawloski denomina a los que muestran escepticismo sobre el carácter «correcto» del Derecho y de su «ciencia» como: la «mala prensa de la dogmática» (die schlechte Presse der Dogmatik, 1991, pp. 6 y 333 y ss.), incluyendo aquí a autores como J. Esser y W. Maihofer. Prescindiendo de estas dificultades, se pueden reconocer dos méritos específicos en la obra de Pawlowski: desmitifica la teoría de las fuentes normativas substituyéndola por una reflexión sobre los «materiales de trabajo jurídicos»; y hace objeto de su reflexión los aspectos de «organización de los tribunales judiciales» dentro del proceso de interpretación de las leyes.

Otros autores que podrían considerarse como miembros de la Jurisprudencia de Valores y que albergan por eso esperanzas en torno a la «racionalidad» del Derecho, a las bondades de la Metodología y a las posibilidades de fundamentación jurídica según unos «valores objetivos», son, por ejemplo, ZIPPELIUS y COING. No obstante, ellos han logrado conjugar esas esperanzas con una prudencia que les hace ser cautos en sus afirmaciones. Así, por ejemplo, Zippelius (1994, prólogo) y ADOMEIT con su reciente «Teoría del Derecho para estudiantes» (1998, prólogo) se consideran abiertamente como «racionalistas críticos» y seguidores de Karl Popper. En el caso de Zippelius, junto con el austriaco WOLGANG VOGEL, han tratado de desarrollar lo que ellos denominan una «Teoría del Derecho Experimental», en la cual se acude a la tesis del Racionalismo Crítico de que toda teoría que se ofrezca en el marco jurídico debe constituir un intento de solución (un «experimento» en sentido amplio) respecto a ciertos problemas concretos.

\section{La corriente sistémica y autopoiética del Derecho}

El téorico de más renombre en Alemania en este momento, después de (o junto con) Habermas es NIKLAS LUHMANN. Ello se debe con seguridad a que la Teoría de Sistemas de Luhmann pretende ser «una teoría universal de la vida en el mundo y no sólo una mera teoría de la sociedad o del Derecho» (Röhl, 2001, p. 424). Este autor está caracterizado pues, aparte de por su gigantesca producción, por ejercer una notable influencia también en la Teoría del Derecho. Es usual encontrarse actualmente en los escritos sobre esta materia con una buena cantidad de conceptos tales como: «complejidad», «contingencia», «reducción de la complejidad», «totalidad», «autorreferencia», «paradoja», «recursividad», entre otros. La influencia de Luhmann se extiende no sólo al ámbito de la Teoría general del Derecho, sino que sus conceptos son aplicados también en áreas muy específicas. Tal es el caso, por ejemplo, del Derecho Penal donde Günther Jakobs, valién- 
dose de nociones de la Teoría de Sistemas ha desarrollado su polémico enfoque de la Teoría del Delito. Este es el caso también del Derecho procesal, donde Luhmann ha ejercido una influencia palpable al punto de considerársele como uno de los pocos autores que ha creado una «verdadera» teoría procesal (en especial con su obra de 1969: Legitimation durch Verfahren).

Lo que le ha valido una gran popularidad a Luhmann a lo interno de la Teoría del Derecho -aparte de su habilidad para crear nuevos términos y abigarradas tramas conceptuales- es, desde mi punto de vista, dos aspectos muy concretos:

a. Su empleo «bondadoso» de la noción de «sistema»y

b. Su concepto de «autopoiesis»

En cuanto al primer punto se refiere, es claro que el concepto de «sistema» si no se define claramente se presta para una infinidad de cosas. Lo cierto es que uno de los usos de ese concepto es precisamente un uso retórico y emotivo que sirve para legitimar la idea, ya de por sí arraigada en la mentalidad del jurista, de que el Derecho constituye de alguna forma un «sistema» con contornos bien marcados. Así, por ejemplo, Büllesbach (en: AA.VV. [1994b], p. 373) siguiendo a Georg Klaus nos dice que desde el punto de vista sociológico: «un sistema es un conjunto de elementos y un conjunto de relaciones que existen entre esos elementos». Por supuesto, que siguiendo una definición de este tipo no se facilitan para nada las cosas. Así pues, en lugar de definir la noción de «sistema» lo que se suele hacer es ofrecer un conjunto de atributos o de elementos que son importantes para su comprensión. Se dice, así, que un sistema posee tres atributos esenciales: a. La autorregulación o homeostasis, b. La autoconservación o autopoiesis y c. El autodesarrollo o evolución (véase Röhl, 2001, p. 422).

Un aspecto que facilita la comprensión de la actual Teoría de Sistemas es tener presente que uno de los antecesores de esa corriente es el Organicismo. Según esta concepción, la sociedad se comporta como un organismo vivo, donde cada una de las partes o miembros del organismo cumple una función específica y sin la cual el «todo» no podría subsistir. Estas ideas se transfieren como tal a la sociedad, sólo que en lugar de «miembros» se habla ya de «sub-sistemas cibernéticos» y en el lugar de la «materia» se colocan los «flujos de comunicación», etc. El Derecho constituye dentro de la Teoría de Sistemas uno de los «sub-sistemas» más importantes.

La idea organicista a la que me he referido se aprecia con especial claridad en la noción de «autopoiesis», la cual fue desarrollada en un inicio como un concepto propio de la biología (véase Neves, 1996). Ella apunta en lo esencial a la posibilidad de auto-organización que poseen los organismos (y también algunos sub-sistemas sociales como el Derecho). «Los sistemas autopoiéticos se renuevan y se reproducen constantemente mediante una di- 
námica que nunca se detiene, pero que, sin embargo, aparece como plenamente estable» (Büllesbach, en: AA.VV. [1994b], p. 392). Me parece que como metáfora la idea de «sistema autopoiético» puede resultar interesante. No obstante, como una descripción realista de lo que es el Derecho esta idea se queda corta, pues es indudable que el Derecho no se comporta como un sistema auto-suficiente (autopoiético), sino que está inextrincablemente vínculado y depende en muchos casos de otros «sub-sistemas» sociales como son la política y la economía.

\section{Otras Corrientes (Neo-institucionalismo, concepciones analíticas, retóricas, hermenéuticas, postmodernas, Análisis económico del Derecho)}

Una posición interesante en la Teoría del Derecho de los últimos tiempos es la defendida por OTA WEINBERGER (junto con MacCormick) y conocida como Neo-Institucionalismo o como Positivismo Institucional. Esta corriente busca realizar una meta que bien podría considerarse por algunos como imposible de llevar a cabo, a saber: superar el abismo lógico que existe entre el ser (Sein) y el deber (Sollen). Se trata por ello de una «ontología jurídica» que se encuentra, según sus autores, «más allá del Positivismo Jurídico y del Derecho natural» (Weinberger, 1985, pp. 140 y ss.) y con ello también «más allá del normativismo y del realismo jurídicos» (Weinberger, 1985, pp. 15 y ss.). La pregunta clave es: ¿Cómo es que Weinberger quiere superar este abismo? Para ello se vale de algunos conceptos centrales en su concepción. En primer lugar, se ofrece la categoría de «acción», la cual «constituye una característica fundamental del ser humano» (Weinberger, 1994, p. 10) y que se define como «un comportamiento intencional dirigido según ciertos criterios de información». Se debe distinguir entre dos tipos de información: la información descriptiva y la información práctica. Es dentro de este último tipo de información en el cual se incluyen las normas del Derecho, las cuales se orientan a determinar distintas posibilidades de acción humana.

La teoría de la acción desarrollada por Weinberger guarda estrecha relación con su concepto de «Institución». Esto ya que es por medio de las acciones reguladas según cierta información práctica como las personas construyen sus instituciones. Una institución se define como «un marco normativo para la acción e interacción humana» (Weinberger, 1994, p. 11). De las instituciones se derivan los «hechos institucionales». De allí que Weinberger define la tesis central del Neo-Institucionalismo de la siguiente forma: «Entre las instituciones y los hechos institucionales por un lado, y la información práctica (por ejemplo, la que se ofrece a través de las normas jurídicas) por el otro, existe un vínculo necesario. Toda institución posee un núcleo de información práctica que justifica la existencia y el funcionamiento 
de la institución» (Weinberger, 1994, p. 11). De esta forma se garantiza el vínculo entre las instituciones y las normas jurídicas. Por ejemplo, las normas relativas al acto de «casarse» sólo tienen sentido dentro de la institución «matrimonio». De allí deriva Weinberger el concepto de «vigencia» del Derecho. Éste es, me parece a mí, uno de los aspectos más interesantes de su teoría. Es conocido que tanto las tradiciones ius-naturalistas como las positivistas han tenido enormes dificultades para fundamentar la categoría de «vigencia». Los primeros se valen de una presunta «objetivación» de los valores (ubicados, finalmente, en un reino más allá de lo humano) para inferir de allí la vigencia y la autoridad del Derecho. En el caso de los segundos (los positivistas) se debe recurrir: o bien a la ficción de una «norma fundamental» o bien a una autoridad axiológicamente predefinida (la Constitución, el Legislador, etc.), derivando de esa autoridad la respuesta a la pregunta: ¿por qué rige el Derecho? La propuesta de Weinberger para responder a esta interrogante es interpretar la «vigencia» del Derecho de la siguiente forma: «Un ordenamiento jurídico como un sistema dinámico rige (o sea tiene vigencia) en una determinada sociedad únicamente cuando existe, como fundamento del sistema normativo, una existencia institucional (institutionelles Dasein), es decir, cuando en la sociedad existe un conjunto de hechos institucionales que representan la base del sistema normativo» (Weinberger, 1994, p. 12).

Las corrientes analíticas no han experimentado obviamente en Alemania el mismo éxito que tienen en el ámbito anglosajón, donde la tradición se remonta hasta Bentham, pasando por J. Austin, H.L.A. Hart y extendiéndose hoy día hasta autores como Joseph Raz. Sin embargo, ella no ha dejado de tener sus efectos. Uno podría distinguir - por comodidad- entre dos vertientes de la Teoría del Derecho analítica: a la primera se le podría llamar la vertiente lingǘstica y a la segunda la vertiente lógico-formal. Las dos tesis centrales de la primera línea de trabajo se pueden resumir de la siguiente forma:

a. Todo Derecho está ineluctablemente acuñado en un lenguaje. Como fenómeno lingüístico él debe separarse de las dos otras manifestaciones de lo jurídico, a saber: del Derecho como un fenómeno social y como un fenómeno psicológico. Una distinción nítida de estas tres esferas resulta indispensable para mantener la «higiene» metodológica y evitar así confusiones. La dogmática jurídica, por ejemplo, justifica su actividad en virtud de esta distinción. Ella estudia las normas como si fueran entidades lingüísticas o lógicas con una existencia autónoma y de allí como si fueran «inmunes» frente a la realidad (Savigny, E. en: AA.VV.[1976], p. 106). Esto no implica, por supuesto, que todos los dogmáticos sean analíticos (pues más bien es el caso contrario), sino tan sólo que a éstos les resulta de utilidad un 
tratamiento puramente normativo del Derecho. En fin, la función de la teoría analítica del Derecho es, según la vertiente lingüística, lograr claridad sobre los conceptos que se emplean, pero sin preocuparse de sus efectos reales o de sus conexiones meta-jurídicas (políticas, económicas, ideológicas).

b. Todo Derecho debe separarse obligatoriamente de la moral. No es, por supuesto, que el Derecho no contenga elementos morales, sino que para efectos de su estudio deben manejarse como campos distintos. De allí que un Derecho abiertamente injusto, una «injusticia legal» (como diría Radbruch) sigue siendo Derecho, o inversamente, una costumbre moral por muy justa que sea no tiene porque ser Derecho. Algunos autores representativos de la línea analítica en Alemania son, por ejemplo: H.J. KOCH (con sus trabajos de 1982, 1977 y 1972); MAZURECK (en: AA.VV. [1994b]), ECKMANN (1969), y en algún grado E. v. SAVIGNY (en: AA.VV. [1976]).

Ahora bien, si se interpreta la corriente analítica, no específicamente en su dimensión de filosofía del lenguaje, sino en un sentido más amplio, entonces es posible ubicar dentro ella los desarrollos importantes que se han logrado en el campo de: a) la lógica jurídica, b) la Teoría de las Normas, c) la llamada «Wissenschaftstheorie der Rechtswissenschaft»), y d) la Informática Jurídica.

En lo referente a la lógica jurídica es posible encontrar actualmente en circulación una serie de trabajos importantes (desde los clásicos de KLUG, 1951; ENGISCH 1943; RÖDIG, 1969; WEINBERGER, 1970, hasta los más recientes: HERBERGER/SIMON, 1980, NEUMANN, 1986, RATSCHOW, 1998; SCHNEIDER, 1999, entre otros). El desarrollo que ha tenido la lógica en el Derecho es considerable y cada vez más difícil de seguir por los juristas. Se ha ido desde los análisis tradicionales sobre el silogismo, pasando por la lógica proposicional y posteriormente por la lógica de predicados hasta llegar a la lógica deóntica. Hoy día se pretende incluso aplicar la llamada «Fuzzy Logic» a los problemas jurídicos (e.g. KRIMPHOVE, 1999). Este tipo de lógica se contrapone a la lógica formal pues pretende ser una lógica aplicable en aquellos casos donde la información es imprecisa, incompleta o incluso contradictoria y donde, por consiguiente, la lógica tradicional no es de utilidad. Una crítica de estas corrientes es imposible de realizar aquí, limitándonos únicamente a transcribir la sentencia de Röhl: «Toda decisión jurídica es en su núcleo a-lógica» (2001, p. 114).

En lo atinente a la Teoría de las Normas, la cosa no es menos complicada que en el ámbito de la lógica (véase, e.g., PHILIPPS, en: AA.VV. [1994b], pp. 317 y ss.). Allí se ha llegado también a complejas elaboraciones -valiéndose de la ayuda de la lógica deóntica y de diagramas como los de Venn- en torno a las categorías de: mandamiento, prohibición, permi- 
sión, etc., alcanzando ya niveles a veces difíciles de comprender. Pero también han surgido aquí obras de mayor alcance. Tal es el caso de la llamada Juristische Methodik (1995) de FRIEDRICH MÜLLER. Este autor quiere desarrollar una especie de técnica de alcance general que sirva para concretar las normas (Normkonkretisierung) a partir del análisis de los casos jurídicos particulares (Müller, 1995, p. 23). La teoría que él desarrolla, denominada: «strukturierende Methodik», pretende ser un marco general dentro del cual hay que incluir a la Metodología Jurídica, a la Hermenéutica, a la Teoría de la interpretación, convirtiéndose así en una concepción totalizante de la norma.

En lo relativo a la «Wissenschaftstheorie der Rechtswissenschaft», han surgido aquí discusiones importantes. El núcleo central de esta orientación consiste en tomar el Derecho como «objeto de investigación» partiendo para ello de la Teoría de las Ciencias y analizando los paralelismos y las diferencias entre las estructuras de otras disciplinas y aquellas del Derecho. Es decir, nos encontramos aquí con una especie de «meta-teoría» de la ciencia jurídica. Algunos de los temas que se discuten allí son los siguientes: el carácter de cientificidad o no del Derecho, el empleo o no de métodos de las ciencias naturales, la aplicabilidad o no del principio de verificación o del de falsación, los problemas de fundamentación empírica, la naturaleza de la dogmática y, por último, el importante tema relativo a la utilidad o no de las ciencias sociales para el mejoramiento de la investigación jurídica. Algunos trabajos importantes en esta línea son los de: E. v. SAVIGNY (en: AA.VV. [1976]), NEUMANN (1986), HANS ALBERT (1978, 1993), R. DREIER (1981).

Por último, el desarrollo que se ha dado también en la Informática Jurídica es considerable, especialmente si se tiene en cuenta que éste es un enfoque del Derecho que pretende llevarse a la práctica en todas las ramas jurídicas. Los desarrollos más importantes se ubican en áreas como: la protección de datos, los sistemas expertos, los sistemas de documentación y la cibernética jurídica. Existe, sin embargo, desacuerdo sobre cuáles son los contornos exactos de la disciplina y cuáles sus objetos de estudio (SCHNEIDER, en: AA.VV. [1994b], pp. 504 y ss.). También los vínculos con las teorías tradicionales del Derecho o con la filosofía jurídica son problemáticos.

Hoy día es posible encontrar autores que se adhieren directamente a otras corrientes no menos importantes. La retórica es un ejemplo de lo anterior. Obviamente el trabajo aquí clásico es el de VIEHWEG; sin embargo, circulan también en la actualidad otra serie de textos en la misma dirección (F. HAFT, 1985; W. GAST, 1992). Igualmente, en el ámbito de la Hermenéutica es posible encontrar algunos trabajos de importancia (HASSEMER, 1984; KAUFMANN, 1984). Un problema central que ocupa a estos estu- 
dios es el del «círculo hermenéutico» (o de acuerdo al concepto creado por Hassemer: la «espiral hermenéutica»). Se trata aquí de un intento de reflexionar sobre el problema de las «preconcepciones» y el papel que juegan éstas en la actividad jurídica. En especial Hassemer es un autor que suele mantener una actitud crítica respecto a la Teoría del Derecho y a la Metodología jurídica (ello a pesar de que sus trabajos principales se ubican en el campo del Derecho penal). Por otro lado, las Teorías marxistas del Derecho o las concepciones derivadas directamente de la Teoría Pura, se encuentran momentáneamente en una fase de parcial receso.

Otras corrientes téoricas recientes como, por ejemplo, las Teorías postmodernas del Derecho (véase LADEUR, 1992) o el Critical Legal Studies $(C L S)$ no han podido encontrar en Alemania un terreno fértil para su cultivo. Sin embargo, el principal atractivo de estas corrientes radica en su actitud crítica frente a lo que se considera el «ideario tradicional de la Modernidad». La columna vertebral de estas orientaciones, en especial de las postmodernas, está constituida por un pronunciado escepticismo respecto a las categorías de «razón», de «verdad», de «justicia», de «emancipación», de «libertad», las cuales constituyen, según ellas, los grandes mitos o las grandes «narraciones» dominantes de Occidente. En contraposición a este ideario, los «postmodernos» (a pesar de la gran cantidad de autores y corrientes que se agrupan bajo ese rubro) quieren exaltar el carácter fingido e incluso arbitrario que subyace en todo este discurso. La actitud postmoderna enfatiza más bien la contingencia del mundo, lo efímero de la experiencia, lo rebuscado y artificioso de las teorías y de los sistemas, lo postizo y decadente de los grandes ideales. «Las verdades del humanismo, la confianza en el hombre y demás ingenuidades, ya sólo poseen un valor de ficciones, una prosperidad de sombras. Occidente era esas verdades; ya no es más que esas ficciones, esas sombras. Tan miserable como ellas no puede verificarlas. Las arrastra, las expone, pero ya no las impone; han dejado de ser amenazadoras...» (Cioran, 1997, p. 69). El suyo es, pues, un llamado a la incertidumbre, un manifiesto a la duda, pero también una oda a lo diferente, a lo pequeño, en fin, a lo otro (y de allí la afinidad entre estas concepciones y los movimientos feministas o de otras minorías, explicación clara en Röhl, pp. 298-301). El centro intelectual de las corrientes postmodernas o del CLS sigue siendo, sin lugar a dudas, Francia (Derrida, Lyotard) y Estados Unidos.

En cuanto al Análisis económico del Derecho se refiere, la situación en Alemania no es muy distinta a la de las dos corrientes referidas, pues, a diferencia de lo que sucede en los Estados Unidos, éste encuentra aquí muy pocos cultores (los más importantes son: LEHMANN, 1983, SCHÄFER/OTT, 1986 y más recientemente EIDENMÜLLER, 1998). A esta 
orientación se le suele criticar, muchas veces sin un conocimiento detallado de sus contenidos, que ella reduce la totalidad del Derecho a un mero «naturalismo» y al ser humano a un mero homo oeconomicus o que transforma la justicia en un asunto de «eficiencia» o que desconoce los «principios jurídicos fundamentales», los cuales no están siempre sujetos a puros criterios de rendimiento o de coste-beneficio, etc. (véase Martin, 1991). Sin embargo, se trata de una orientación que requiere una atención especial y cuyos méritos principales son, desde mi punto de vista, dos:

- Es una corriente teórica arraigada en una estructura epistemológica científicamente criticable y discutible intersubjetivamente. Esto hace de ella una corriente de corte realista en el sentido expuesto más arriba. Los enunciados que ella produce se encuentran, por lo general, enraizados en investigaciones de corte empírico y no puramente especulativo. Sobre los posibles vínculos ideológicos del Análisis Económico del Derecho con determinadas corrientes político-económicas es un tema que todavía hay que estudiar.

- Es una orientación teórica que ha logrado hacer efectivos algunos vínculos interdisciplinarios del Derecho con otras disciplinas empíricas (e.g. la Economía, la Estadística, la Matemática), sin descuidar por ello los fundamentos axiológicos (piénsese aquí en la discusión de base en torno al Utilitarismo o al Consecuencialismo que existe entre sus defensores). Se facilita de esta forma la comunicación de los juristas con otros científicos sociales y todo ello a nivel internacional, lo cual ha sido históricamente una preocupación de la Teoría del Derecho. No obstante, también debe reconocerse que el empleo técnico de algunas categorías (piénsese aquí, por ejemplo, en nociones como «óptimo de Pareto», «teorema de Coase», «principio de Kaldor/Hicks», etc.) tienden a tener un efecto «intimidatorio» entre los jurístas, no familiarizados con el lenguaje propio de la Economía.

Es en el sentido acotado en los dos puntos anteriores que EIDENMÜLLER se esfuerza (partiendo de las tesis de Albert) por lograr una visión crítica y realista del Derecho, entendido éste como una ciencia real. De allí que sostenga que: «Si uno mantiene en mente que la función más importante del Derecho está en constituir un instrumento para el control y orden de los procesos sociales, entonces debe resultar claro cuál debe ser el interés central de una ciencia jurídica, a saber: la obtención de un conocimiento sobre las correlaciones causales de la realidad que sea utilizable instrumentalmente...» (Eindenmüller, 1999, página 54). La obra principal de Eidenmüller por el momento es Effiziens als Rechtsprinzip (La eficiencia como principio jurídico) donde el autor trata de explorar no sólo las ventajas y límites del Análisis Económico del Derecho, sino también en qué tanto y 
medida se puede considerar la «eficiencia» como una categoría central de la ciencia jurídica. Es una obra que merece atención.

\section{Literatura citada en el trabajo*}

AA.VV. [1996]: Garzón Valdés, E. y Laporta, F.J., El derecho y la justicia, Madrid; AA.VV. [1991]: Alexy, R., Dreier, Ralf y Neumann, Ulfrid, «Rechts- und Sozialphilosophie in Deutschland heute. Beiträge zur Standortbestimmung, Archiv für Rechts- und Sozialphilosophie (ARSP), Suplemento Nr. 44; AA.VV. [1994a]: Simon, D., Rechtswissenschaft in der Bonner Republik, Frankfurt/M.; AA.VV. [1994b]: Kaufmann, A., Hassemer, W., Einführung in Rechtsphilosophie und Rechtstheorie der Gegenwart, Heidelberg; AA.VV. [1976]: Neumann, U./Rahlf,J.,/von Savigny, E., Juristische Dogmatik und Wissenschaftstheorie; AA.VV. [1969]: Adorno, Th., Popper, K., Dahrendorf, R., Habermas, J., Albert, H., Pilot, H., reimpresión, Hamburgo, 1993; Adomeit, K., Rechtstheorie für Studenten, 1998; Albert, H., Rechtswissenschaft als Realwissenschaft. Das Recht als soziale Tatsache und die Aufgabe der Jurisprudenz, 1993 (texto que forma parte de este libro); el mismo, Zur Kritik der reinen Jurisprudenz. Recht und Rechtswissenschaft in der Sicht des kritischen Rationalismus, 1992 (texto que forma parte de este libro); el mismo, Transzendentale Träumereien, 1975; el mismo, Traktat über kritische Vernunft, 1991; Alexy, R., Theorie der juristischen Argumentation, 1991; Atienza, M., Derecho y Argumentación, 1997; Bydlinski, F., Juristische Methodenlehre und Rechtsbegriff, 1991; Brunner, E. Die Gerechtigkeit. Eine Lehre von den Grundgesetzen der Gesellschaftsordnung, 1943; Canaris, W. Systembegriff und Systemdenken in der Jurisprudenz, 1969; Cioran, E.M., Silogismos de la Amargura, 1997; Coing, H., Grundzüge der Rechtsphilosophie, 1993; Dreier, R., Zum Begriff der «Natur der Sache», 1965; el mismo, RechtMoral-Ideologie, 1981; el mismo, Hauptströmungen gegenwärtiger Rechtsphilosophie in Deutschland, en la revista: Archiv für Rechts- und Sozialphilosophie Nr. 81, 1995; Eckmann, H., Rechtspositivismus und Sprachanalytische Philosophie. Der Begriff des Rechts in der Rechtstheorie H.L.A. Hart, 1969; Eidenmüller, H., Effizienz als Rechtsprinzip, 1999; el mismo, Rechtswissenschaft als Realwissenschaft, en: Juristen Zeitung 54, 1999; Engisch, K. Logische Studien zur Gesetzesanwendung, 1943; el mismo, Einführung in das juristische Denken, 1997; Esser, J. Vorverständnis und Methodenwahl in der Rechtsfindung, 1970; el mismo, Grundsatz und Norm in der richterlichen Fortbildung des Privatrechts, 1956; Fuchs, J., Lex

\footnotetext{
* Para efectos de simplificación y para ahorrar espacio cito aquí únicamente el nombre del autor, el título de la obra y el año de edición del texto consultado.
} 
naturae. Zur Theologie des Naturrechts,1955; Funk, J., Primat des Naturrechts. Die Transzendenz des Naturrechts gegenüber dem positiven Recht, 1952; Gast, W., Juristische Rhetorik. Auslegung, Begründung, Subsumtion, 1992; Haba, E.P., Standortbestimmung zeitgenössischer Rechtstheorie -Rawls, Dworkin, Habermas und andere Mitglieder der «Heiligen (Rede-) Familie», en: Rechtstheorie 27, 1996; Habermas, J., Faktizität und Geltung, 1992, el mismo, Wahrheitstheorien, en: Fahrenbach, H., (Editor), Wirklichkeit und Reflexion, 1973; Haft, F., Juristische Rhetorik, 1985; Hassemer, W., (Editor), Dimensionen der Hermeneutik, Arthur Kaufmann zum 60. Geburtstag, 1984; Heinz, W., (Editor), Rechtstatsachenforschung, 1998; Herberger, M./Simon, D., Wissenschaftstheorie für Juristen, 1980; Kaufmann, A., Analogie und «Natur der Sache», 1965; el mismo (como editor), Rechtstheorie. Anätze zu einen kritischen Rechtsverständnis, 1971; el mismo, Beiträge zur juristischen Hermeneutik, 1984; Hilgendorf, E., Hans Albert zur Einführung, 1997; el mismo, Argumentation in der Jurisprudenz. Zur Rezeption von analytischer und kritischer Theorie in der Grundlagenforschung der Jurisprudenz, 1991; Kaupen, W., Die Hüter von Recht und Ordnung, 1969; Keuth, H. Erkenntnis oder Entscheidung. Zur Kritik der kritischen Theorie, 1993; Koch, H.J., (Editor), Juristische Methodenlehre und analytische Philosophie, 1976; el mismo, Die juristische Methode im Staatsrecht, 1977; el mismo (junto con Rüßmann, H.), Juristische Begründungslehre, 1982; Klug, U., Juristische Logik, 1951; Kriele, M., Theorie der Rechtsgewinnung, 1976; el mismo, Recht und praktische Vernunft, 1979; Krimphove, D., Der Einsatz von Fuzzy-Logik in der Rechtswissenschaft, en: Rechtstheorie 30, 1999; Ladeur, Postmoderne Rechtstheorie. Selbstreferenz-SelbstorganizationProzeduralisierung, 1992; Lautmann, R., Justiz -die stille Gewalt-, 1970; Larenz, K. Methodenlehre der Rechtswissenschaft, 1991; Lehmann, M., Bürgerliches Recht und Handelsrecht -eine juristische und ökonomische Analyse, 1983; Luhmann, N., Legitimation durch Verfahren, 1969; Maihofer, W., (editor), Rechtstheorie. Beiträge zur Grundlagendiskussion, 1971; Martin, S., Ist das Recht mehr als eine blosse soziale Tatsache?, en: Rechtstheorie 22, 1991; Messner, J., Das Naturrecht. Handbuch der Gesellschaftsethik, Staatsethik und Wirtschaftsethik,1950; Müller, F., Juristische Methodik, 1995; Neves, M., De la autopoiesis a la alopoiesis del Derecho, Doxa 19, 1996: Neumann, U., Juristische Argumentationslehre, 1986; Oksaar, E., Sprache als Problem und Werkzeug der Juristen, en: ARSP 53, 1967; Opp, K.D./Peukert, R., Ideologie und Fakten in der Rechtssprechung,1971; Pawlowski, Methodenlehre für Juristen, 1991, el mismo, Einführung in die juristische Methodenlehre, 1986; Peters, D., Richter im Dienst der Macht,1973; Radbruch, G., Rechtsphilosophie, 
Studienausgabe, 1999; Ratschow, E., Rechtswissenschaft und formale Logik, 1998; Rehbinder, M., Rechtssoziologie, 2000; Rödig, J., Die Denkform der Alternative in der Jurisprudenz, 1969; Röhl, K.F., Allgemeine Rechtslehre. Ein Lehrbuch, 2001; el mismo Rechtssoziologie, 1987; Rommen, H., Die ewige Wiederkehr des Naturrechts, 1947; Rüthers, B., Rechtstheorie, 1999 (la cual el sucrito tiene el gusto de traducir al español y que se publicará por la Editorial Temis, Colombia); el mismo, Das Ungerechte an der Gerechtigkeit, 1993; el mismo, Die unbegrenzte Auslegung -Zum Wandel der Privatrechtsordnung im Nationalsozialismus, 1997; el mismo, Entartetes Recht, 1989; el mismo, Rechtsordnung und Wertordnung, 1986; Schäfer, H.-B./Ott, C., (Editores), Allokationseffizienz in der Rechtsordnung, 1988; Schneider, E., Logik für Juristen, 1999; Sprenger, G., Naturrecht und Natur der Sache, 1976; Viehweg, T., Topik und Jurisprudenz, 1953; Von Büllow, O., Gesetz und Richteramt (1885), Reimpresión, 1972; Weinberger, O., Rechtslogik,1970; el mismo (junto con MacCormick, N.), Grundlagen des Institutionalistischen Rechtspositivismus, 1985; el mismo, Realismus und Systemtheorie in der Jurisprudenz, en: Rechtstheorie 25, 1994; Weyrauch, W., Zum Gesellschaftsbild der Juristen, 1970; Welzel, H., Naturrecht und materiale Gerechtigkeit (1951), 4. Reimpresión,1980; Zippelius, R., Rechtsphilosophie, 1994. 